\title{
COELIAC DISEASE
}

\section{Interleukin 18 and associated markers of $\mathrm{T}$ helper cell type 1 activity in coeliac disease}

\author{
V M Salvati, T T MacDonald, M Bajaj-Elliott, M Borrelli, A Staiano, S Auricchio, \\ R Troncone, G Monteleone
}

See end of article for authors' affiliations

.....................

Correspondence to: $G$ Monteleone, Division of Infection, Inflammation, and Repair, School of Medicine, Southampton General Hospital, MailPoint 813, Level E, South Academic Block, Tremona Road,

Southampton SO16 6YD, UK;

g.monteleone@soton.ac.uk

Accepted for publication 1 May 2001

\begin{abstract}
Background: Coeliac disease (CD) is caused by a T helper cell type 1 (Th 1) response in the small intestinal mucosa to dietary gluten. Paradoxically, interleukin (IL)-12, the major Th 1 inducing factor, is undetectable in the mucosa of active CD. IL-18 is a recently described cytokine capable of promoting T cell interferon (IFN)- $\gamma$ production and facilitating Th 1 cell polarisation.

Aim: To examine expression of IL-18 and IL-18-associated Th 1 proteins in CD.

Methods: IL-18 and IFN- $\gamma$ RNA transcripts were determined by quantitative reverse transcriptasepolymerase chain reaction (RT-PCR). IL-18 and caspase-1 protein expression were assessed by western blotting. Caspase-1 activity was determined using a commercially available assay. RNA transcripts for the IL-18 receptor subunits, IL-1 receptor related protein (IL-1 Rrp) and accessory protein-like subunit (AcPL), and IL-1 8 induced Th 1 specific T box transcription factor (T-bet) were measured by RT-PCR and Southern blotting.

Results: IL-1 8 RNA transcripts were found in all mucosal samples analysed, with no difference between $C D$ patients and controls. By western blot analysis, a large protein of approximately $24 \mathrm{kDa}$, corresponding to the immature IL-18, was detected in all mucosal samples from CD patients and controls. In contrast, mature IL-18 was only seen in CD patients. Immunoreactivity corresponding to both immature and mature caspase- 1 was present in both CD and control samples. Tissue homogenates from CD patients and controls expressed similar levels of caspase-1 activity. IL-1 Rrp and AcPL were seen in all samples but were expressed at greater levels in the mucosa of CD patients. T-bet was also upregulated in CD.
\end{abstract}

Conclusions: Active IL-18 is expressed in CD as well as other markers of Th 1 polarisation.
Abbreviations: $C D$, coeliac disease; IFN, interferon; IL, interleukin: T-bet, T box transcription factor; IL-1Rrp, interleukin 1 receptor related protein; AcPL, accessory protein-like; RT-PCR, reverse transcriptase-polymerase chain reaction; ICE, IL-1 $\beta$ converting enzyme; Th1, T helper cell type 1. 
with active Crohn's disease undergoing colonoscopy and four patients with irritable bowel syndrome. All four Crohn's disease patients were not receiving treatment and had lesions confined to the colon. The study received ethics approval from the local committee (University Federico II, Naples, Italy).

\section{Preparation of synthetic RNA for quantitative RT-PCR}

To allow quantitation of IL-18 RNA transcripts by reverse transcriptase-polymerase chain reaction (RT-PCR), we constructed a competitor DNA molecule containing specific primer sequences encoded in exon 1 (7-33 bp) and exon 5 (11230-11 252 bp) of the genomic human IL-18 sequence. The primer sequence was as follows: sense $5^{\prime}:{ }^{7}$ GCTGCTGAACCAGTAGAAGACAATTGC ${ }^{33} 3^{\prime}$ and antisense $5^{\prime}:{ }^{11252}$ CCTTGATGTTATCAGGAGGATTC $^{11230} 3^{\prime}$. The above primer sequences were cloned into plasmid pMBEK, as described in detail previously. ${ }^{16}$ To generate standard RNA, the plasmid was linearised with HindIII and transcribed in vitro using T7 RNA polymerase under conditions recommended by the supplier (Promega, Biotech, Milan, Italy). Using the same primer set, RT-PCR for standard IL-18 yielded a PCR product of $478 \mathrm{bp}$ whereas the test size was $384 \mathrm{bp}$. IFN- $\gamma$ mRNA transcripts were also measured by competitive RT-PCR, as described previously. ${ }^{17}$

\section{RNA extraction, cDNA preparation, and quantitative RT-PCR}

Total RNA was extracted from whole mucosal duodenal biopsies from 16 active CD patients (median age two years; range 0.8-17.8) and 14 normal controls (median age 8.3 years; range 1.6-14) using the Trizol reagent (Gibco Life Technologies, Milan, Italy) according to the manufacturer's instructions, and quantified at $260 \mathrm{~nm}$. The integrity of RNA was checked by electrophoresis on a $1.5 \%$ agarose gel. A constant amount of tissue RNA (0.2 $\mu \mathrm{g}$ for IL-18 and $1 \mu \mathrm{g}$ for IFN- $\gamma$ ) and serial 10-fold dilutions of synthetic RNA ( 1 pg to $0.1 \mathrm{fg}$ ) were cotranscribed into complementary cDNA in a $20 \mu \mathrm{l}$ reaction mixture containing $50 \mathrm{mM}$ Tris, $\mathrm{pH} 8.3,75 \mathrm{mM} \mathrm{KCl}, 3 \mathrm{mM}$ $\mathrm{MgCl}_{2}, 500 \mu \mathrm{M}$ each dATP, dCTP, dTTP, and dGTP (Pharmacia Biotech, Milan, Italy), 10 mM DTT, 0.5 jg oligo (dT) 12-18 $_{\text {(Phar- }}$ macia Biotech), and 100 U MMLV-RT (Gibco Life Technologies). A $5 \mu \mathrm{l}$ sample of cDNA was then amplified under the following conditions: denaturation for one minute at $94^{\circ} \mathrm{C}$, annealing for one minute at $58^{\circ} \mathrm{C}$ for IL- 18 and $60^{\circ} \mathrm{C}$ for IFN- $\gamma$, and extension for one minute 15 seconds at $72^{\circ} \mathrm{C}$ for 37 cycles. Products were visualised on a $2 \%$ agarose gel using Vistra-Green dye (Amersham International, Milan, Italy). Densitometric analysis of fluorescent bands was carried out on STORM-860 by ImageQuant software (Molecular Dynamics, Inc, Sunnyvale, California, USA). The ratio of standard/ target RNA was plotted against the starting number of standard RNA molecules on a double logarithmic scale to determine the molecule content in the sample for each transcript. Results are expressed as number of transcripts/ $\mu g$ total RNA.

\section{Southern blot analysis}

RNA expression of IL-1Rrp, AcPL, and T-bet was assessed semiquantitatively by Southern blotting. In preliminary experiments we established the optimal number of cycles to obtain a PCR product within the linear phase of the amplification. For this purpose, an equivalent amount of cDNA for sample was amplified using specific primers for $\beta$-actin ( $1 \mu$ of cDNA for 23, 25, and 27 cycles), IL-1Rrp ( $2 \mu \mathrm{l}$ of cDNA for 27, 30 , and 33 cycles), AcPL ( $2 \mu \mathrm{l}$ of cDNA for 28,30 , and 32 cycles), and T-bet ( $2 \mu \mathrm{l}$ for 33,35 , and 40 cycles). PCR reactions were performed from $1 \mathrm{\mu g}$ of total RNA in a total volume of $50 \mu \mathrm{l}$. For Southern blot experiments, cDNA samples were amplified with $\beta$-actin primers for 23 cycles, with IL-1Rrp for 30 cycles, with AcPL for 28 cycles, and with T-bet for 33 cycles. The primers were as follows: T-bet sense 5' GAGGGTCGCGCT-
CAACAAC 3' and antisense 5' GGATGCTGGTGTCAACAGATG 3'; IL-1Rrp sense 5' CCAGAAGGCAAATGGCATGCTTC 3' and antisense 5' CAACAGCTCCTCCAGGCACTAC 3'; AcPL sense 5' TCAGACGCTTGGGGATAAAA $3^{\prime}$ and antisense $5^{\prime}$ CAAGTAACTGTGGGCAAAACC $3^{\prime}$. $\beta$-actin primers have been published previously. ${ }^{12}$ To exclude amplification of genomic DNA contaminating the samples, experiments were also performed using RNA as substrate for PCR assay. The PCR conditions were denaturation for one minute at $94^{\circ} \mathrm{C}$, annealing for one minute $\left(58^{\circ} \mathrm{C}\right.$ for IL- 1 Rrp, $53^{\circ} \mathrm{C}$ for AcPL, $55^{\circ} \mathrm{C}$ for T-bet and $\beta$-actin), and extension for one minute 15 seconds at $72^{\circ} \mathrm{C}$. The CDNA probes were DNA fragments encoding the full length PCR product. RT-PCR products were run on a $1 \%$ agarose gel and Southern blotting was performed according to a commercially available chemiluminescence detection kit (Amersham International).

Tissue homogenate preparation and western blotting Protein analysis was performed on whole mucosal duodenal samples from 12 active CD patients (median age four years; range $0.8-57$ ), one adult treated $C D$, one latent $C D$ ( 10 years), and seven normal controls (median age 6.4 years; range 1.440). Biopsy specimens were placed in sterile tubes and homogenised using a tissue homogeniser in $300 \mu \mathrm{l}$ of lysis buffer containing $25 \mathrm{mM}$ Tris/ $\mathrm{HCl}, \mathrm{pH}=8,50 \mathrm{mM} \mathrm{NaCl}$, $10 \mu \mathrm{g} / \mathrm{ml}$ leupeptin, $2 \mu \mathrm{g} / \mathrm{ml}$ benzamidine, $20 \mu \mathrm{g} / \mathrm{ml}$ aprotinin, $50 \mu \mathrm{g} / \mathrm{ml}$ soybean trypsin inhibitor, $1 \mathrm{mM}$ ethylene glycol-bis ( $\beta$-aminoethyl ether) tetraacetic acid (EGTA), and $100 \mathrm{\mu g} / \mathrm{ml}$ phenylmethylsulphonylfluoride (all available from Sigma, Milan, Italy). After cell lysis the supernatant was collected, spun at $12000 \mathrm{rpm}$ for 20 minutes $\left(4^{\circ} \mathrm{C}\right)$, and stored at $-70^{\circ} \mathrm{C}$.

For detection of IL-18 or caspase-1, $50 \mu \mathrm{g}$ of total protein were denatured by boiling for five minutes in Laemmli's sample buffer and separated on a 15\% sodium dodecyl sulphatepolyacrylamide gel and electrophoretically transferred onto nitrocellulose membranes (Amersham) for $1-2$ hours at $4^{\circ} \mathrm{C}$ at $100 \mathrm{~V}$. IL- 18 and caspase- 1 protein were detected after incubation with a goat antihuman IL-18 ( 1:500 final dilution) or goat antihuman caspase-1 antibody (1:400 final dilution) (Santa Cruz Biotechnology, Santa Cruz, California, USA) recognising the active p20 subunit of caspase- 1 . The membrane was then incubated with horseradish peroxidase conjugated rabbit antigoat IgG monoclonal antibody (Dako, Cambridgeshire, UK) (final dilution 1:2500) and the reaction detected with ECL Plus kit (Amersham International). To confirm equal loading and transfer of proteins, ponceau S (Sigma) staining was performed.

\section{Colorimetric caspase-1 assay}

Total protein $(80 \mu \mathrm{g})$, diluted to a volume of $50 \mu \mathrm{l}$ with lysis buffer, was mixed with $50 \mu \mathrm{l}$ of reaction buffer (100 mM Hepes, pH 7.5, 10\% glycerol, 5 mM DTT, 0.5 mM EDTA) and incubated at $37^{\circ} \mathrm{C}$ for two hours in the presence of $200 \mu \mathrm{M}$ caspase-1 substrate (Alexis Biochemicals, Lausen, Switzerland). Products of the reactions were read at $450 \mathrm{~nm}$ in a microtitre plate reader and normalised to the negative control.

\section{Statistical analysis}

Statistical analysis was performed using the non-parametric Mann-Whitney test for two independent samples.

\section{RESULTS}

Analysis of IL-18 gene and protein expression in the mucosa of active coeliac disease

To confirm that the CD lesion is associated with a preferential Thl response, we first analysed the amount of transcripts for IFN- $\boldsymbol{\gamma}$, the major Thl lymphocyte derived cytokine, in the mucosa of patients with $\mathrm{CD}$ and controls. CD patients exhibited levels of IFN- $\gamma$ RNA transcripts significantly higher than controls (CD: median 91 021 (range 2605-183 433) 


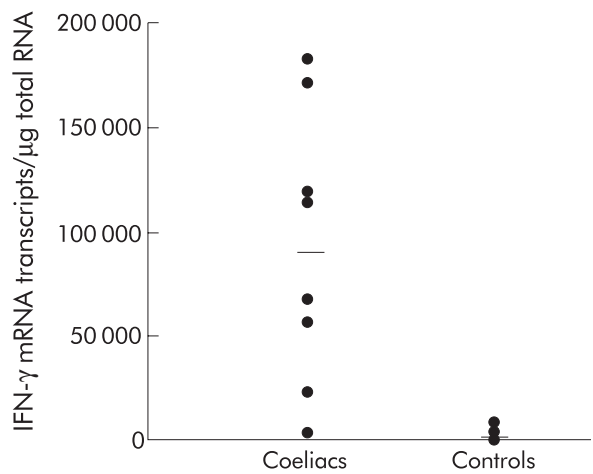

Figure 1 Interferon $\gamma$ (IFN- $\gamma$ ) mRNA transcripts in duodenal biopsies from eight patients with coeliac disease and 11 normal controls. Each point indicates the number of transcripts/ $\mu \mathrm{g}$ total RNA in the mucosal sample taken from a single patient or control. Bars represent the median. In coeliac patients, IFN- $\gamma$ mRNA transcripts were significantly increased compared with controls $(p<0.0002)$.

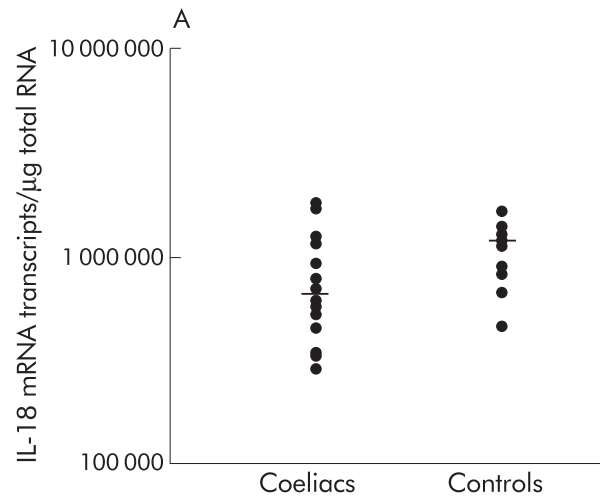

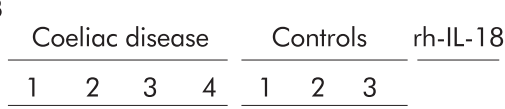

$24 \mathrm{kDa}$

$18 \mathrm{kDa}$

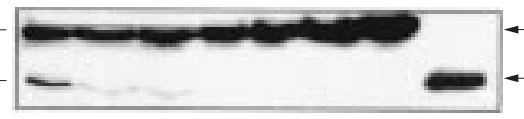

4Pro-IL-18

- Mature IL-18

Figure 2 (A) Interleukin (IL)-18 mRNA transcripts in duodenal biopsies from 16 patients with coeliac disease and 14 normal controls. Each point indicates the number of transcripts/.jg total RNA in the mucosal sample taken from a single patient or control. Bars represent the median. No significant difference was observed. (B) Representative western blot of IL-1 8 in duodenal mucosal tissue from four patients with coeliac disease and three normal controls. The sample shown in lane 4 was taken from a patient with coeliac disease on a gluten free diet. Anti-IL-1 8 antibody detected a protein corresponding to the size of human recombinant IL-18 in all coeliac disease samples but not in controls. A $24 \mathrm{kDa} \mathrm{IL-1} 8$ was also detected in all samples from coeliac disease patients and controls. Sizes of protein standards are given. One representative experiment of two independent experiments is shown.

transcripts/pg total RNA; controls: median 1047 (range 227-8271) transcripts/pg total RNA; p<0.0002) (fig l).

We then determined IL-18 RNA content by quantitative RT-PCR in the same samples analysed for IFN- $\gamma$. IL-18 RNA transcripts were detected in all mucosal samples with no significant difference between active $C D$ patients and controls (CD: median 645463 (range 285 315-1 797 792) transcripts/pg total RNA; controls: median 1183899 (range 470 106-1 613 114) transcripts/pg total RNA) (fig 2A). To examine whether IL-18 was regulated at the posttranscriptional level, IL-18 protein was analysed in $10 \mathrm{CD}$
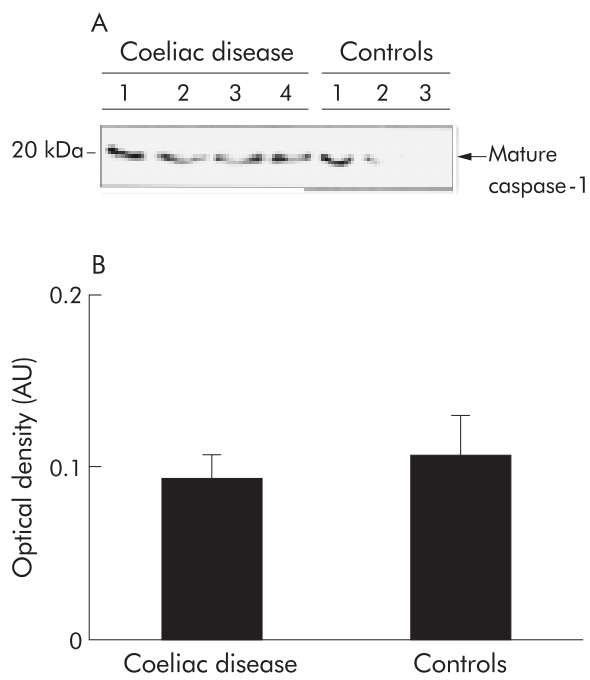

Figure 3 (A) Representative western blot of caspase-1 in duodenal mucosal tissue from patients with coeliac disease and normal controls. Samples were the same as those analysed for IL-18 in fig 2B. Caspase-1 antibody detected a protein of $20 \mathrm{kDa}$ corresponding to the mature form in both coeliac disease and control samples. One representative experiment of two independent experiments is shown. (B) Levels of caspase-1 activity in mucosal samples from four coeliac disease patients and three controls. Functional assay was performed as indicated in materials and methods. Optical density was read at $450 \mathrm{~nm}$ and the results expressed as arbitrary units. Values are mean (SEM). Caspase-1 activity was not significantly different in coeliac disease and control samples.

patients and four normal controls by western blotting. In all CD patients and controls, the anti-IL-18 antibody detected a larger protein of approximately $24 \mathrm{kDa}$ (fig $2 \mathrm{~B}$ ). As we used a polyclonal antibody reacting with an epitope corresponding to an amino acid sequence mapping at the carboxy terminus of the human IL-18 precursor, the $24 \mathrm{kDa}$ corresponds to the immature IL-18. In contrast, a protein of approximately 18 kDa comigrating with recombinant IL-18 and corresponding to the mature form of IL-18 was seen in 9/10 CD patients (including the treated and latent CD patient) but not in controls (fig 2B).

\section{Active caspase- 1 expression in the small intestinal mucosa of coeliac disease and control patients}

Production of mature IL- 18 requires the presence of the intracellular cysteine proteinase caspase- 1 which is capable of converting immature IL- 18 into the mature form. ${ }^{8}$ Caspase- 1 is synthesised as a $45 \mathrm{kDa}$ polypeptide precursor and subsequently cleaved into a mature form of 20 and $10 \mathrm{kDa} .{ }^{8}$ Immunoreactivity corresponding to mature caspase- 1 was present in both CD and controls (fig 3A). Consistently, tissue homogenates from four $C D$ patients and three normal controls expressed similar levels of caspase-1 activity (CD patients: mean 0.09 (SEM 0.014); controls: mean 0.107 (SEM 0.023)) (fig 3B).

\section{IL-1 Rrp and AcPL gene expression is upregulated in coeliac disease patients}

Both IL-18 receptor subunits, IL-1Rrp and AcPL, have been reported to be expressed at high levels during Thl responses, thereby maintaining the functional responsiveness of Th cells to IL-18. ${ }^{18}$ Therefore, we assessed whether IL-18 production was associated with enhanced IL-18R expression in CD mucosa. RNA transcripts for both chains, IL-1Rrp and AcPL, were seen in all mucosal samples from CD patients and controls. However, a more pronounced expression of both IL-18 R subunits was found in CD in comparison with controls (fig 4). There is no commercial antibody capable of specifically 


\begin{tabular}{|c|c|c|c|c|c|c|c|c|c|c|}
\hline \multicolumn{5}{|c|}{ Coeliac disease } & \multicolumn{5}{|c|}{ Normal duodenum } & \\
\hline 1 & 2 & 3 & 4 & 5 & 1 & 2 & 3 & 4 & 5 & \\
\hline$=$ & & & & $\infty$ & - & $=$ & $=$ & & & $\longleftarrow \mathrm{AcPL}$ \\
\hline
\end{tabular}

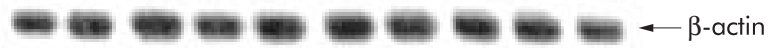

Figure 4 Southern blot analysis of transcripts for accessory protein-like subunit (AcPL) (top blot), interleukin 1 receptor related protein (IL-1 Rrp) (middle blot), and $\beta$-actin (bottom blot) in duodenal mucosa from five patients with coeliac disease and five normal controls. Total RNA $(1 \mu \mathrm{g})$, extracted as indicated in materials and methods, was used for CDNA preparation. CDNA (2 $\mu)$ for AcPL and IL-1Rrp, and $\beta$-actin $(1 \mu l)$ were amplified for 28,30 , and 23 cycles, respectively. Polymerase chain reaction products were then run on an agarose gel, blotted, and hybridised with oligonucleotide probes specific for AcPL, IL-1 Rrp, and $\beta$-actin. One representative experiment is presented out of the 10 coeliac disease and 10 controls studied in total.

and selectively recognising the distinct IL-18R subunits. Therefore, based on these data, we cannot exclude the possibility that the documented differences at the RNA level are not associated with pronounced induction of IL-18R proteins.

\section{Expression of T-bet, an IL-18 induced Th 1 marker}

The mechanism by which IL- 18 facilitates IFN- $\gamma$ production is not yet fully understood. In addition to a direct effect on IFN- $\gamma$ gene promoter, IL-18 has recently been shown to enhance expression of T-bet, a Thl specific T box transcription factor, which directly promotes differentiation of Thl cells. ${ }^{192}$ As shown in fig 5A, T-bet transcripts were consistently present in all samples tested, even if more pronounced expression was seen in CD patients. In addition, T-bet was upregulated in the inflamed mucosa of patients with Crohn's disease, a disorder also associated with enhanced production of active IL-18 (fig 5B).

\section{DISCUSSION}

This study was designed to determine whether IL-18 is produced in the mucosa of CD patients. We found constitutive expression of IL-18 RNA in all intestinal samples tested, with no difference between $\mathrm{CD}$ and controls. In addition, in all CD and control samples, IL-18 RNA was efficiently translated, as indicated by the presence of the $24 \mathrm{kDa}$ inactive protein in western blot experiments. However, the $18 \mathrm{kDa}$ polypeptide, corresponding to the mature IL-18, was only seen in CD patients, raising the possibility that IL-18 in CD mucosa is regulated only at a post-translational level, as suggested in other human diseases and experimental models. ${ }^{112222}$ The cellular source of IL-18 in the CD mucosa remains to be determined. However, previous studies have shown that in the gastrointestinal tract, IL-18 is mainly produced by macrophages, dendritic, and epithelial cells. ${ }^{123}$ Processing of the immature IL-18 into the mature form is mainly mediated by caspase- 1 or IL- $1-\beta$ converting enzyme (ICE). ${ }^{8}$ Caspase- 1 is synthesised as a $45 \mathrm{kDa}$ precursor that is subsequently cleaved into active subunits of 20 and $10 \mathrm{kDa}^{8}$. We found that both CD and control mucosal samples expressed the mature form of ICE and contained similar levels of caspase-1 activity. We do not know if in the normal duodenal mucosa, cells containing immature IL-18 also express active ICE. Our data suggest that

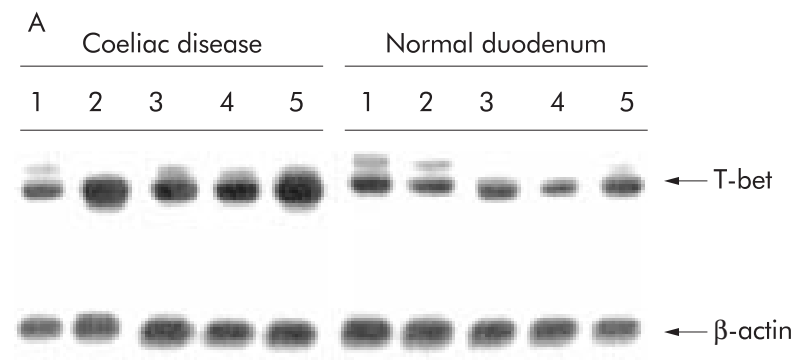

B

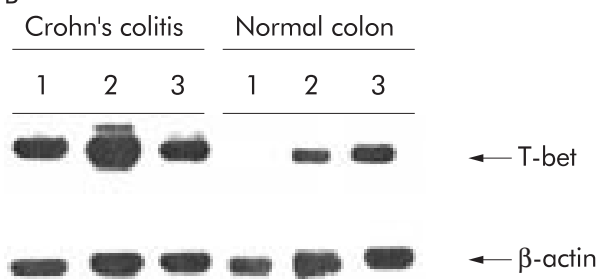

Figure 5 Southern blot analysis of transcripts for T box transcription factor (T-bet) and $\beta$-actin in duodenal mucosa from five patients with coeliac disease and five normal controls $(\mathrm{A})$ and in colonic mucosal samples from three patients with Crohn's disease and three normal controls (B). Total RNA (1 $\mu \mathrm{g})$, extracted as indicated in materials and methods, was used for cDNA preparation. T-bet $(2 \mu)$ and $\beta$-actin $(1 \mu)$ were amplified for 33 and 23 cycles, respectively. Polymerase chain reaction products were then run on an agarose gel, blotted, and hybridised with probes specific for T-bet and $\beta$-actin. For the duodenal specimens, one representative experiment is presented out of the 10 coeliac disease and 10 controls studied in total, while for the colonic samples $3 / 4$ patients with Crohn's disease and 3/4 controls are shown. The other patients showed a similar pattern of response. Consistent upregulation of T-bet mRNA expression was detected in coeliac disease and Crohn's mucosa.

other factors rather than caspase-1 might be involved in the processing of IL-18 in the gastrointestinal mucosa. This hypothesis is also supported by the demonstration that mature IL-18 is efficiently synthesised in caspase-1 deficient mice by a mechanism dependent on the interaction between Fas and Fas ligand, ${ }^{24}$ a pathway which has recently been described in $\mathrm{CD}^{25}$ In this context, it is noteworthy that other caspases or caspase-like proteinases have been reported to cleave immature IL-18. ${ }^{26}$

IL-18 mediated signals are transduced through a receptor composed by two subunits, IL-1Rrp and AcPL, which are mainly expressed on Thl cells in response to IFN- $\alpha$ and/or IL-12. ${ }^{18}$ Consistently, we found that both IL-18R chains were upregulated in CD in comparison with controls. However, we cannot locate which cells express IL-18R as there is no commercial antibody that specifically and selectively recognises both receptor subunits.

T-bet is a specific $\mathrm{T}$ box transcription factor which correlates with IFN- $\gamma$ expression in Thl and natural killer cells. T-bet is responsible for Thl lineage development from naive Th cells and acts both by initiating Thl genetic programmes and by repressing the opposing Th2 cell development. ${ }^{20}$ In this study we showed that T-bet was more pronounced in CD mucosa in comparison with normal duodenum. In addition, T-bet was upregulated in Crohn's disease, another intestinal Thl associated disease, in which IL-18 is markedly upregulated. ${ }^{12}$ The fact that T-bet was found in the normal duodenum and colon is consistent with the demonstration that human intestinal lamina propria is infiltrated with IFN- $\gamma$ secreting cells. ${ }^{27}$ Since in the human intestinal lamina propria of normal subjects the major Thl inducing cytokines are virtually undetectable, it is conceivable that these IFN- $\gamma$ secreting cells come from Peyer's patches, a site in which the high IL-12 facilitates differentiation of Thl cells. ${ }^{271228}$ 
A major histological feature of active CD is the marked infiltration of gluten specific activated $\mathrm{T}$ cells in the lamina propria of the small intestinal mucosa. ${ }^{1}$ Freshly isolated lamina propria $\mathrm{T}$ cells from coeliac patients have increased frequencies of IL- 2 and IFN- $\gamma$ secreting cells. ${ }^{29}$ In addition, the in vitro challenge of $\mathrm{CD}$ biopsies with gliadin induces a rapid increase in the number of CD25 + T cells and elicits high levels of IFN- $\gamma$ transcripts. ${ }^{20}$ Many of these T cells are DQ2 restricted and of a Thl or Th0 type with dominant IFN- $\gamma$ production. ${ }^{31}$ The molecular mechanism involved in the differentiation of Thl cells in CD however remains unknown. A possible mechanism is that naive $\mathrm{T}$ cells recruited from the blood are differentiated in situ along the Thl pathway. Indeed, we have shown recently that in active CD mucosa, there is an exaggerated production of IFN- $\alpha$, a cytokine that promotes Thl cell development. ${ }^{7}$ Moreover, it is likely that Thl cells primed in the Peyer's patches seed the lamina propria of CD patients where locally induced factors may contribute to maintain and expand the gluten specific Thl response. In this context, IL-18 may play a major role, given that IL-18 can enhance IFN- $\gamma$ synthesis and favour Thl cell polarisation induced by either IL-12 or IFN- $\alpha$. $^{32}{ }^{33}$

\section{ACKNOWLEDGMENTS}

This work was supported by the European Union grant (ERBFMRXCT9). It also received financial support from the Commission of the European Communities, specific RTD programme "Quality of Life and Management of Living Resources", QLRT-CT-1999-00037, “Evaluation of the prevalence of coeliac disease and its genetic components in the European population" (it does not necessarily reflect its views and in no way anticipates the Commission's future policy in this area), and by Ministero della Sanita" "Nuove terapie per il morbo coeliaco". Virginia M Salvati received a grant for Young Investigators from the Italian Society for Paediatric Gastroenterology and Hepatology (SIGEP).

\section{Authors' affiliations}

V M Salvati, M Borrelli, A Staiano, S Auricchio, R Troncone, Department of Pediatrics and European Laboratory for the Investigation of Food-Induced Diseases, University Federico II, Naples, Italy

T T MacDonald, G Monteleone, Division for Infection, Inflammation, and Repair, University of Southampton, Southampton, UK M Bajai-Elliott, Department of Paediatric and Adult Gastroenterology, St Bartholomews and the Royal London School of Medicine and Dentistry, London, UK

\section{REFERENCES}

1 Godkin A, Jewell D. The pathogenesis of celiac disease. Gastroenterology 1998:115:206-10.

2 Nilsen EM, Jahnsen FL, Lundin KEA, et al. Gluten induces an intestinal cytokine response strongly dominated by interferon gamma in patients with celiac disease. Gastroenterology 1998;1 15:551-63.

3 MacDonald TT, Spencer J. Evidence that activated mucosal T cells play a role in the pathogenesis of enteropathy in human small intestine. J Exp Med 1988:167:1341-9.

4 Bajaj-Elliott M, Poulsom R, Pender SLF, et al. Interactions between stromal cell-derived keratinocyte growth factor and epithelial transforming growth factor in immune-mediated crypt cell hyperplasia. J Clin Invest 1998; 102:1473-80

5 MacDonald TT, Bajaj-Elliott M, Pender SLF, et al. T cells orchestrate intestinal mucosal shape and integrity. Immunol Today 1999;20:505-10.
6 Janeway CA, Bottolmy K. Signals and signs for lymphocyte responses. Cell 1994;76:275-85.

7 Monteleone G, Pender S.L.F, Alstead E, et al. Role of interferon- $\alpha$ in promoting Thelper cell type 1 responses in the small intestine in coeliac disease. Gut 2001;48:425-9.

8 Dinarello CA. IL-18: a Th 1-inducing proinflammatory cytokine and new member of the IL-1 family. J Allergy Clin Immunol 1999;103:11-24.

9 Torigoe K, Ushio S, Okura T, et al. Purfication and characterization of the human interleukin-18 receptor. J Biol Chem 1997;272:25737-42.

10 Born TL, Thomassen E, Bird TA, et al. Cloning of a novel receptor subunit, AcPL, required for interleukin-1 8 signaling. J Biol Chem 1998;273:29445-50.

11 Gracie AJ, Forsey RJ, Chan WL, et al. A proinflammatory role for IL-18 in rheumatoid arthritis. J Clin Invest 1999;104:1393-1401.

12 Monteleone G, Trapasso F, Parrello T et al. Bioactive IL-18 expression is up-regulated in Crohn's disease. J Immunol 1999;163:143-7.

13 Hong TP, Andersen NA, Nielsen K, et al. Interleukin-18 mRNA, but not interleukin-18 receptor mRNA, is constitutively expressed in islet beta-cells and upregulated by interferon- $\gamma$. Eur Cytokine Netw 2000;11:193-205.

14 Robinson D, Shibuya K, Mul A, et al. IGIF does not drive Th 1 development but synergizes with IL-1 2 for interferon- $\gamma$ production and activates IRAK and NFKB. Immunity 1997;7:571-81.

15 Walker-Smith JA, Guandalini S, Schmitz J, et al. Revised criteria of diagnosis of coeliac disease. Arch Dis Child 1990;65:909-11.

16 Bajaj-Elliott $M$, Breese $E$, Poulsom R, et al. Keratinocyte growth factor in inflammatory bowel disease. Am J Pathol 1997;151:1469-76.

17 Jung HC, Eckmann L, Yang SK, et al. A distinct array of proinflammatory cytokines is expressed in human colon epithelial cells in response to bacterial invasion. J Clin Invest 1995;95:55-65.

18 Sareneva T, Julkunen I, Matikainen S. IFN- $\alpha$ and IL-12 induce IL-18 receptor gene expression in human NK and T cells. J Immunol 2000; 165: 1933-8

19 Barbulescu K, Becker C, Schlaak JF, et al. Cutting edge: IL-12 and IL-18 differentially regulate the transcription activity of the human IFN- $\gamma$ promoter in primary CD4+ T lymphocytes. J Immunol 1998;160:3642-7.

20 Szabo SJ, Kim ST, Costa GL, et al. A novel transcription factor, T-bet, directs Th1 lineage commitment. Cell 2000;100:655-69.

21 Lu H, Shen C, Brunham RC. Chlamydia trachomatis infection of epithelial cells induces the activation of caspase-1 and release of mature IL-18. J Immunol 2000; 165: 1463-9.

22 Tomita T, Jackson AM, Hida N, et al. Expression of interleukin-18, a Th1 cytokine, in human gastric mucosa is increased in Helicobacter pylori infection. J Infect Dis 2001;183:620-7.

23 Pages F, Berger A, Lebe-Binay S, et al. Proinflammatory and antitumor properties of interleukin-18 in the gastrointestinal tract. Immunol Lett 2000;75:9-14.

24 Tsutsui H, Kayagaki N, Kuida K, et al. Caspase-1-independent, Fas/Fas ligand-mediated IL-1 8 secretion from macrophages causes acute liver injury in mice. Immunity 1999;11:359-67.

25 Maiuri L, Ciacci C, Raia V, et al. Fas engagement drives apoptosis of enterocytes of celiac patients. Gut 2001;48:418-24.

26 Fantuzzi G, Dinarello CA. Interleukin-18 and interleukin-1 $\beta$ : two cytokine substrates for ICE (caspase-1). J Clin Immunol 1999;19:1-11.

27 Carol M, Lambrechts A, Van Gossum A, et al. Spontaneous secretion of interferon gamma and interleukin 4 by human intraepithelial and lamina propria gut lymphocytes. Gut 1998:42:643-9.

28 Nagata S, McKenzie C, Pender SLF, et al. Human Peyer's patch T cells are sensitised to dietary antigen and display a Th cell type 1 cytokine profile. J Immunol 2000;165:5315-21

29 Breese EJ, Farthing MG, Kumar P, et al. Interleukin-2 and interferon- $\gamma$ producing cells in the lamina propria in coeliac disease. Dig Dis Sci 1994:39:2243.

30 Haltensen TS, Scott $\mathrm{H}$, Fausa $\mathrm{O}$, et al. Gluten stimulation of coeliac mucosa in vitro induces activation (CD25) of lamina propria CD4+ T cells and macrophages but no crypt-cell hyperplasia. Scand J Immunol 1993;38:581-90.

31 Nilsen EM, Lundin KEA, Krajci P, et al. Gluten-specific HLA-DQ restricted $T$ cells from coeliac mucosa produce cytokines with Th 1 or Th0 profile dominated by interferon- $\gamma$. Gut 1995;37:766-76.

32 Chang JT, Segal BM, Nakanishi K, et al. The costimulatory effect of IL-18 on the induction of antigen specific IFN-gamma production by resting T cells is IL-12 dependent and is induced by up-regulation of the II-12 receptor beta 2 subunit. Eur J Immunol 2000;30:1113-19.

33 Sareneva T, Matikainen S, Kurimoto $M$, et al. Influenza A virus-induced IFN-alpha/beta and IL-1 8 synergistically enhance IFN-gamma gene expression in human T cells. J Immunol 1998;160:6032-8. 